\title{
The individual differentiated training design of health-promoting shaping with mature age women
}

\author{
Kostyuchenko V.F. ${ }^{1 A C D E}$, Skidan A.A. ${ }^{2 A B C D}$, Vrublevskiy E.P. ${ }^{2,3 A B C D E}$ \\ ${ }^{1}$ Faculty of Summer Olympic Sports, National State University of Physical Culture, Sports and Health named after \\ P.F. Lesgafta, Russia \\ ${ }^{2}$ Faculty of Physical Education, Gomel State University named after Fransysk Skarina, Belarus \\ ${ }^{3}$ Faculty of Medicine and Health Sciences, University of Zielona Góra, Poland
}

Authors' Contribution: A - Study design; B - Data collection; C - Statistical analysis; D - Manuscript Preparation; E - Funds Collection.

\begin{abstract}
Purpose: $\quad$ theoretical justification, development, and approbation of individual differentiated training design of healthpromoting shaping with mature age women.

Material: $\quad$ women aged from 21-55 years $(n=86)$ participated in the research. It was determined the initial level of their morphofunctional state and physical fitness (it was considered phases of an individual ovarian menstrual cycle). It was revealed criteria of the individual differentiated approach to the design of health-promoting shaping training (it was considered biorhythms of the female body). It was realized the nine-months macrocycle of health-promoting shaping training. The macrocycle consisted of three stages. Two programs - power and aerobic orientation are developed for training at the main stage of a macrocycle. Distribution of loads, their duration, intensity, and volume was regulated individually. It was considered the hormonal background of a female body during an ovarian menstrual cycle.

Results: It is observed an increase in the level of a morphofunctional state and physical fitness of women. It is revealed statistically reliable changes of all physical development indicators, a functional state and physical fitness of women.

Conclusions: The individual differentiated approach to training design of improving shaping allows to operate a morphofunctional condition of women organism more purposefully. Such an approach promotes organism adaptation to training loads. It also promotes an increase in the level of morphofunctional and physical fitness and health.

Keywords: female body, mature age, shaping program, ovarian menstrual cycle, morphofunctional state, physical fitness.
\end{abstract}

\section{Introduction}

One of the problems of improving physical culture system is increasing in level of health and physical activity of mature age women. Health defines the quality of modern woman life, achievements in the professional sphere [1-3]. The health condition is reflected in all spheres of women lives, and the completeness of life diversity directly depends on the qualitative characteristics of health level. All this defines women's image and lifestyle, the degree of their activity in life and in professional work [4-6].

The last one is especially important for mature age women i.e. in this age period signs of aging begin to appear. The following factors point at this period: the decrease in working capacity; change of body weight structure; increase in a number of chronic diseases; decrease in health, mood, creative activity. The mature age period is one of the critical periods for the woman. During this period the stable stage of organism development is replaced by involution: the weakening of functional activity is observed [7-9]. The presented main characteristics defined interest to this problem at representatives of various fields of knowledge [10, 11].

Scientific research convinces that the sufficient level of physical activity is the dominant factor of aging processes delay: keep and increases in physical capacity

(c) Kostyuchenko V.F., Skidan A.A., Vrublevskiy E.P., 2018

doi:10.15561/18189172.2018.0603 of mature age women [12-14]. Restriction of muscular activity at mature age leads to detraining and deregulation and imperfect adaptable mechanisms [15-17]. Therefore middle age women are the category which is the least involved in sports and improving the process. The middle age women need systematic tanning [18-21].

The interest in shaping stipulates high relevance of scientific research. The data obtained by various authors allow to improve the methodology of this type of physical activity $[4,14,20]$. It is also important the fact that pedagogical design in modern conditions becomes one of the main trends of development and updating of sports and improving work in pedagogical science and practice $[8,18]$.

Pedagogical design provides forming of strategy and the plan of training improving programs for the selected category of persons [8]. At the same time, the pedagogical activity has to pass from reproductive (blind copying of activity) into qualitatively new productive (innovative). The last one is directed to development and approbation of new, more effective ways of process design of individual's improvement.

Hypothesis. The improving shaping training with mature age women will become pedagogically expedient and effective if the organization process will be projected on the basis of individual differentiated shaping programs. At the same time, the biorhythmic phases of the female body have to be considered. 
The purpose of the research is theoretical justification, development, and approbation of the individual differentiated technique of improving shaping training design with mature age women. The consideration of biological regularities of organism functioning is obligatory.

\section{Material and methods}

Participants. Women aged from 21-55 years $(\mathrm{n}=86)$ participated in a research. Women were engaged in the sports and improving center (Gomel State University named after Fransysk Skarina, Belarus). The informed consent to participation in an experiment was received from all participants.

Design of a research. It was applied an anthropometrical method (assessment of physical development), methods of functional diagnostics (monitoring of a cardiovascular and respiratory system, express assessment of physical health condition by G.L. Apanasenko's technique, assessment of physical working capacity $-\mathrm{PWC}_{170}$ test), pedagogical testing (determination of physical fitness level).

The following sequence of carrying out a research was chosen for the achievement of the purpose. At the first stage was performed determination of women's initial level of morphofunctional state and physical fitness. Morphofunctional diagnostics and determination of physical fitness level consider phases of the individual ovarian menstrual cycle (OMC). The above-mentioned researches were conducted for each woman in the same, optimum - post-menstrual (6-12 day from the beginning of a cycle) or-post-ovulation phases (16-24 day from the beginning of a cycle).

The main tasks' plan of improving shaping process was defined at the second stage.

The general scheme of the individual differentiated technique design of improving shaping training was developed at the third stage (Fig. 1).

Planning of shaping training programs was performed by the fundamental principle of periodicity: microcycles, mesocycles, and macrocycles are defined. The ninemonths macrocycle (September-May) of improving shaping training is realized. The macrocycle consisted of three stages: preparatory, the main and stabilizing.

The preparatory stage lasted 6 weeks ( 1 mesocycle). The main tasks were diagnostics of body kinetics condition, adaptation of a female body to training loads, the design of individually differentiated corrective shaping programs.

The main (developing) stage lasted 24 weeks (4 mesocycles). Its purpose was a transition to a higher level of physical health condition, correction of a body constitution, change of muscular topography. It was necessary to raise a functional condition of respiratory and cardiovascular systems, to strengthen the musculoskeletal system, to correct the level of physical fitness.

The stabilizing stage lasted 6 weeks ( 1 mesocycle) and was directed to the maintenance of the reached level in a morphofunctional condition of women and their motor abilities.

Shaping program of training consisted of several parts which differed in various target orientation. In general, (developing) stage of a macrocycle was developed two programs of training - power and aerobic orientation.

The structure of shaping training of power and aerobic orientation is designed by the block principle. The shaping training program of power orientation included: sets of exercises oriented to force development of the main muscular groups; increase of bones density. It promoted prevention of osteoporosis and increase of exchange processes intensity. Shaping program of aerobic

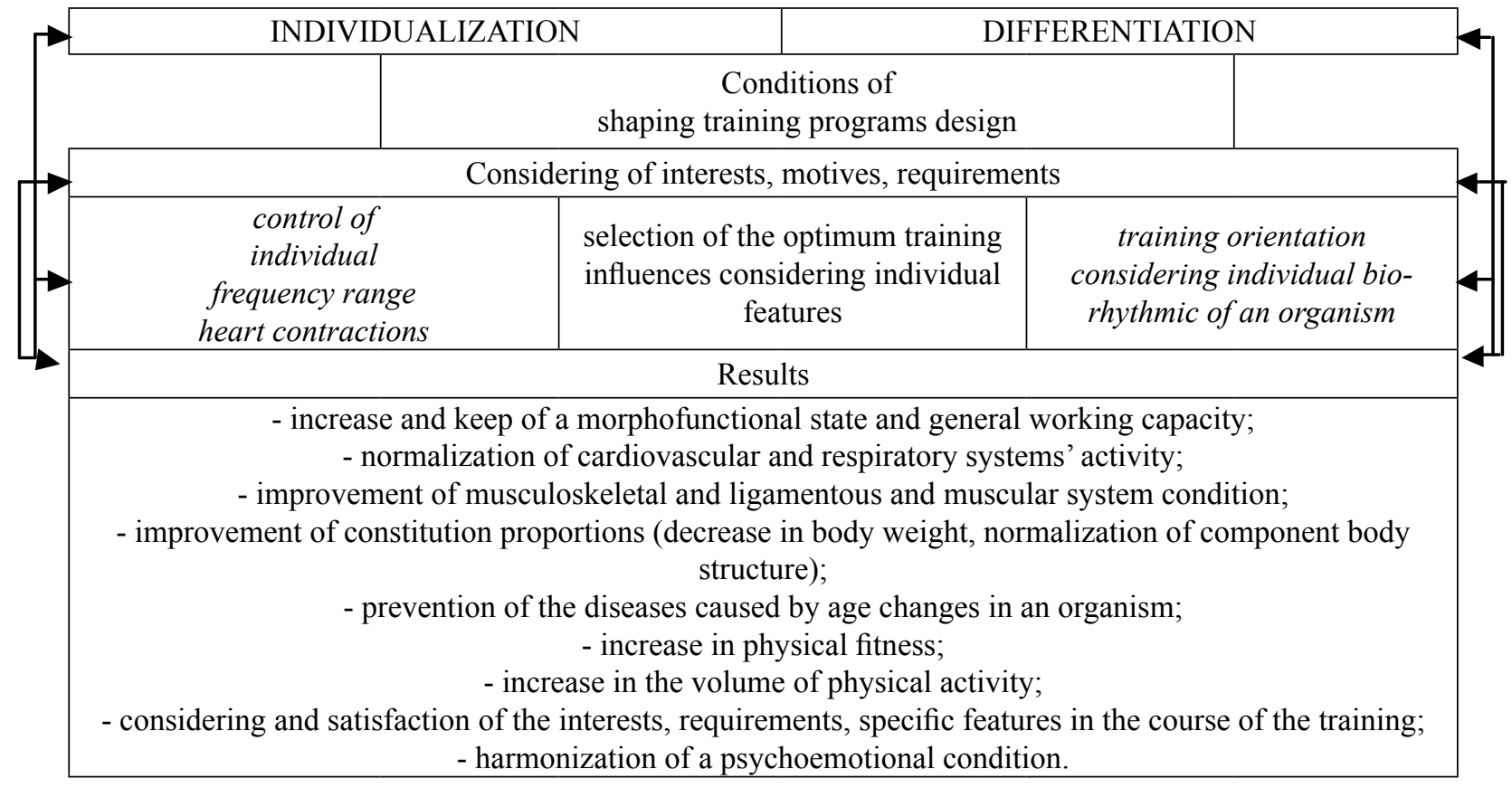

Fig. 1. The scheme of the individual differentiated technique design of improving shaping training. 
orientation training contained sets of exercises devoted to increase in functionality of an organism.

The individual and group method was applied in training design. The purposes and contents of the program were equal for all participants. Distribution of loads, their duration, intensity, and volume was regulated individually (the hormonal background of a female body during OMC was considered) [22, 23]. The beginning and the end of a microcycle is caused by the duration of each phase of biorhythmic of certain woman organism (Tab. 1).

Every training the experimental group was divided into three subgroups according to an individual functional condition of women.

In the first subgroup were women who are in premenstrual, menstrual and ovulatory phases. In the second subgroup were women who are in post-menstrual phase (it was applied the catabolic load directed to decrease of fat mass). In the third subgroup were women who are in postovulatory phase (it was applied the anabolic training influences directed to increase in muscle mass). It allowed to differentiate improving process. Depending on this or that phase of OMC women had a possibility to choose a subgroup.

Women of each subgroup at the same time were engaged in the certain motor sector with the individual video instructor. Such an approach substantially protected women organisms of physical and psychophysiological overloads. During improving shaping training the contents of sets were corrected for each woman. Training sets were three times a week and their duration was 60 minutes.

At the final stage was evaluated the efficiency of the developed technique of improving shaping training design. It was defined the dynamics and reliability of indicators changes in physical development, functional state, and physical fitness.
Statistical analysis. In the processing of experimental data were calculated arithmetic mean $(\overline{\mathrm{X}})$, errors of arithmetic mean $(\mathrm{m})$, variation coefficient $(\mathrm{V} \%)$. The Student's test ( $\mathrm{t}$ ) was applied for checking the reliability of differences between two average selective means. The difference was considered significant at $p<0,05$.

\section{Results}

At the initial stage of a research were estimated the initial level of physical development, functional condition, physical fitness of women. It was revealed deviations from standard values of the majority of indicators.

Data of initial level of women physical development indicators at the end of an experiment are presented in table 2.

The indicator of body weight is exceeded in $18.7 \%$ (on average $11 \mathrm{~kg}$ ). The body mass index (BMI) is exceeded in $11.3 \%$. It demonstrates the presence of overweight and is estimated as preobesity. The similar variability is traced also in indicators of the body structure. The fat content in women organism is considerably exceeded (the optimum level of a fat component is in the range from 18 to $25 \%$ ).

The decrease in $21.7 \%$ is revealed in the analysis of a muscular component. The optimum level of this component is in the range from 34 to $36 \%$. Therefore, it is determined the low level of muscle mass development at the beginning of the experiment. Such a situation is caused by the low level of women physical activity. It leads to increase in fat body mass and decrease in muscle mass.

Outside the norms of development there are indicators of a functional condition: the vital capacity of lungs (VCL) is in $15.2 \%$; the heart rate (HR) is in $11.8 \%$; the arterial blood pressure (ABP) in $6.7 \%$; results of breath holding test in $13.7 \%$; the indicator of the general work

Table 1. Structure of the mesocycle constructed according to biorhythmic phases of women organism.

\begin{tabular}{llll}
\hline Microcycle duration & OMC phases and their duration & Total training load & Motor mode \\
\hline Recovering & Premenstrual 3-4 days, & Average & $50-60 \%$ \\
6-8 days & Menstrual 3-5 days & Small & HR max \\
$\begin{array}{l}\text { Developing } \\
\text { 7-9 days }\end{array}$ & Postmenstrual (estrogenic) 7-9 days & Big & $60-70 \%$ \\
Stabilizing & Ovulatory & & HR max \\
3-4 days & 3-4 days & Average & $50-60 \%$ \\
$\begin{array}{l}\text { Developing } \\
\text { 7-9 days }\end{array}$ & Postovulatory (progestrogen) 7-9 days & Big & HR max \\
\hline
\end{tabular}

Note: $\mathrm{HR}$ - heart rate; OMC - ovarian menstrual cycle.

Table 2. Dynamics of women physical development indicators $(\overline{\mathrm{X}} \pm \mathrm{m})$

\begin{tabular}{lllll}
\hline Indicators & $\begin{array}{l}\text { Body weight, } \\
\mathbf{( k g )}\end{array}$ & $\begin{array}{l}\text { Body mass index } \\
\left(\mathbf{k g} / \mathbf{m}^{2} \mathbf{)}\right.\end{array}$ & Fat component (\%) & $\begin{array}{l}\text { Muscular } \\
\text { component (\%) }\end{array}$ \\
\hline Before experiment & $70,5 \pm 3,2$ & $25,6 \pm 0,9$ & $33,8 \pm 4,2$ & $26,6 \pm 0,5$ \\
After experiment & $61,2 \pm 1,2^{*}$ & $22,2 \pm 0,7^{*}$ & $25,2 \pm 0,8^{*}$ & $33,6 \pm 1,2^{*}$ \\
Change,\% & 13,2 & 13,3 & 25,4 & 26,3 \\
\hline
\end{tabular}

Note. * - significance of differences according to Student's test at $p<0,05$. 
capacity $\mathrm{PWC}_{170}$ in $10.2 \%$ (Tab. 3 ).

It is determined the low initial level of physical health (the technique of G.L. Apanasenko [22] was applied). Indicators of the body mass, length and vital index are on the level below the average. Force of wrist muscles in relation to body weight is at a low level. The functional index and time of HR recovery (after 20 squats in $30 \mathrm{~s}$ ) correspond to the level below the average (Tab. 4).

Low level of women physical health is caused by overweight, discrepancy of VLC value to age, a reduced power indicator. It is observed the increased arterial blood pressure which is slowed down time of HR recovery after the dosed physical activity.

Level of initial physical fitness of women is also below of standard indicators. It is observed the decrease in indicators in women: force - in $44.4 \%$; general endurance
- in $34.5 \%$; power endurance - in $38 \%$; flexibility - in $30.7 \%$; high-speed and power abilities - in 16.5\%; explosive force - in $6.2 \%$. (Tab. 5).

The data analysis revealed statistically significant changes on all indicators in comparison with source values (Tab. 2-5). It is observed the increase in the level of women morphofunctional condition under the influence of training. It is revealed the decrease in body weight indicator in $9.3 \mathrm{~kg}$. It also caused statistically significant $(p<0,05)$ reduction of BMI value characterizing proportionality of physical development. At the same time, the percentage of fat became less. It is demonstrated by the assessment of body component structure. The fat component in women organism decreased by $25.4 \%$. The muscular component increased by $26.3 \%$. In general, characteristics of body structure reached the standard indicators.

Table 3. Dynamics of women functional condition indicators $(\bar{X} \pm m)$

\begin{tabular}{lllllll}
\hline Indicators & VCL $(\mathbf{m l})$ & $\begin{array}{l}\text { HR at rest } \\
(\mathbf{b p m})\end{array}$ & $\begin{array}{l}\text { Systolic blood } \\
\text { pressure } \\
(\mathbf{m m ~ H g})\end{array}$ & $\begin{array}{l}\text { Diastolic blood } \\
\text { pressure } \\
(\mathbf{m m ~ H g})\end{array}$ & $\begin{array}{l}\text { Stange's } \\
\text { test }(\mathbf{s})\end{array}$ & $\begin{array}{l}\text { PWC } \\
\mathbf{1 7 0} \\
\mathbf{k g m} / \mathbf{m i n} /\end{array}$ \\
\hline $\begin{array}{l}\text { Before } \\
\text { experiment }\end{array}$ & $2922,6 \pm 30$ & $82,3 \pm 1,3$ & $134,2 \pm 3,7$ & $82,3 \pm 2,8$ & $35,4 \pm 4,6$ & $10,9 \pm 0,3$ \\
$\begin{array}{l}\text { After experiment } \\
\text { Change,\% }\end{array}$ & $3272,6 \pm 81^{*}$ & $72,3 \pm 1,6^{*}$ & $122,8 \pm 1,9 *$ & $73,8 \pm 1,5^{*}$ & $45,7 \pm 2,9 *$ & $12,2 \pm 0,3^{*}$ \\
\hline
\end{tabular}

Note. * - significance of differences according to Student's test at $p<0,05$.

Table 4. Dynamics of indicators level of women physical (somatic) health ( $\widetilde{\mathrm{O}}_{ \pm m}$ )

\begin{tabular}{|c|c|c|c|c|}
\hline \multirow{2}{*}{$\begin{array}{l}\text { Indicators } \\
\text { (indexes) }\end{array}$} & \multicolumn{4}{|c|}{$21-55$ years $(n=86)$} \\
\hline & $\begin{array}{l}\text { Before } \\
\text { experiment }\end{array}$ & Level & $\begin{array}{l}\text { After } \\
\text { experiment }\end{array}$ & Level \\
\hline $\begin{array}{l}\text { body mass and length (mass/ body length, gr/ } \\
\mathrm{cm} \text { ) }\end{array}$ & $425,7 \pm 19,3$ & low average & $369,2 \pm 7,2^{*}$ & $\begin{array}{l}\text { above } \\
\text { average }\end{array}$ \\
\hline Vital ( VCL /body mass, ml/kg) & $41,4 \pm 1,3$ & low average & $53,4 \pm 0,3^{*}$ & $\begin{array}{l}\text { above } \\
\text { average }\end{array}$ \\
\hline $\begin{array}{l}\text { Force ( dynamometry of wrist } \\
\text { / body weight } x 100, \% \text { ) }\end{array}$ & $34,9 \pm 1,4$ & low average & $51,7 \pm 1,7^{*}$ & average \\
\hline $\begin{array}{l}\text { Functional (Robinson), HR x ( Systolic blood } \\
\text { pressure / } 100 \text { c.u.) }\end{array}$ & $110,4 \pm 4,8$ & low average & $88,7 \pm 3,4^{*}$ & average \\
\hline $\begin{array}{l}\text { Time of HR recovery after } 20 \text { squats in } 30 \text { s } \\
\text { (min) }\end{array}$ & $2,1 \pm 0,2$ & low average & $1,6 \pm 0,1^{*}$ & average \\
\hline General assessment of health level (score) & $-3,1 \pm 0,3$ & low & $7,1 \pm 0,5^{*}$ & average \\
\hline
\end{tabular}

Note. * significance of differences according to Student's test at $p<0,05$.

Table 5. Dynamics of indicators of physical fitness of women $( \pm m)$

\begin{tabular}{llllll}
\hline Indicators & $\mathbf{2} \mathbf{k m}$ run & $\begin{array}{l}\text { Adam's } \\
\text { forward bend } \\
\text { test }(\mathbf{c m})\end{array}$ & $\begin{array}{l}\text { Cadence } \\
\text { Push-Up Test, } \\
\text { quantity of } \\
\text { times }\end{array}$ & $\begin{array}{l}\text { Bent Arm } \\
\text { Hang Test (two } \\
\text { hands), (s) }\end{array}$ & $\begin{array}{l}\text { Standing long } \\
\text { jump (cm) }\end{array}$ \\
\hline Before experiment & $15,54 \pm 1,31$ & $3,9 \pm 0,7$ & $4,5 \pm 0,8$ & $7,5 \pm 0,2$ & $120,5 \pm 0,8$ \\
After experiment & $12,18 \pm 1,24^{*}$ & $7,2 \pm 1,5^{*}$ & $10,1 \pm 0,9^{*}$ & $13,4 \pm 0,3^{*}$ & $129,1 \pm 0,9 *$ \\
Change,\% & 21,8 & 84,6 & 124,4 & 78,6 & 7,1 \\
\hline
\end{tabular}

Note. ${ }^{*}$ - significance of differences according to Student's test at $p<0,05$. 
Level of vital capacity of lungs (VCL) increased in $350 \mathrm{ml}$. The following indicators decreased at rest: HR in 10 beats/min; systolic arterial blood pressure in 11.4 $\mathrm{mm} \mathrm{Hg}$; diastolic in $8.5 \mathrm{~mm} \mathrm{Hg}(\mathrm{p}<0,05)$. Results of functional tests also considerably improved. First of all, it concerns timed inspiratory capacity test (increase in $10.3 \mathrm{~s}$ ) and PWC170 test (increase in $1.3 \mathrm{kgm} / \mathrm{min} / \mathrm{kg}$ ). These changes reach statistically significant values in $5 \%$ of significant value.

The level of women physical health is also increased. The augmentation was 10.2 points $(p<0,05)$ and reached to "average" assessment of health functional level. As a result of the analysis and systematization of these test exercises the significant increase in the studied indicators was revealed $(\mathrm{p}<0,05)$.

\section{Discussion}

Results of initial morphofunctional diagnostics of women at the 21-55 years are confirmed with results of scientists' researches concerned age involution changes [7, $8,15]$ of physical development indicators, functionality, level of physical fitness. We confirmed and added with the data information from other authors' researches $[1,10$, 24] concerning the low health level of mature age women. It allowed to reveal the low level of physical (somatic) health of women of this age.

The number of works $[1,8,10]$ includes data concerning the existence of close interrelation between the ability of women to transfer physical activity and phases of an ovarian menstrual cycle. It is noted that the dynamics of women efficiency is affected significantly by changes of the hormonal status [23, 25]. In our research feature of monitoring of a morphofunctional state and physical fitness of women of mature age is considering of phases of individual ovarian menstrual cycle. Our researches were performed for each woman in an optimum phase (post-menstrual or - post-ovulation).

Modern experts of improving physical culture $[1,8$, 13] have a general consensus that it is necessary to apply the differentiated approach to optimization of women psychophysical condition in the course of the improving training. However often such differentiation is performed on the basis of the techniques which consider mainly gender and age standards of physical and functional fitness of women.
We offer another approach. In our research, we choose a more rational and high-quality way of application means and methods of improving physical culture. All this corresponded to specific features of a female body in the maximum degree.

We developed a technique of the individual differentiated design of improving shaping training with mature age women. The feature of such technique is the organic combination of specific features of mature age women and phases of their specific biological cycle. It substantially protects women organism from physical and psychophysiological overloads.

The content of shaping programs assumes the selective choice of means in the form of physical exercises sets which are easily combined. Rational motor loads allow to operate more purposefully morphofunctional improvement of the organism of mature age women and to reach a higher level of their physical fitness.

The advantage of our methodology is the result of an increase in the level of morphofunctional and physical fitness, the health condition of mature age women. It is reached after the end of a nine-months macrocycle of the individual differentiated shaping training.

We confirmed and added information of other authors $[1,20,25,26]$ concerning the positive influence of occupations shaping on physical conditions of women of mature age.

\section{Conclusions}

1. The individual differentiated approach to improving shaping training design allows to operate more purposefully morphofunctional improvement of an organism of mature age women. It also allows to reach the optimum level of physical health and physical fitness.

2 . The technique of the individual differentiated design of improving shaping training with mature age women includes the organic combination of consideration of their specific features, phases of their specific biological cycle. It promotes the achievement of a higher cumulative effect of organism adaptation to training loads, increases in the level of morphofunctional and physical fitness, health condition.

\section{Conflict of interests}

The authors declare that there is no conflict of interests.

\section{References}

1. Mamylina NV. Biological features of sports and improving occupations for women. Chelyabinsk: Cicero; 2016. (in Russian)

2. Armstrong T. Physical activity and health benefits. 14th World Conference Sport for All: Abstracts Book. Beijing; 2011. P. 46-49.

3. Serpa JC, Castillo E, Gama AP, Gimenez FJ. Relationship between physical activity, body composition and body image in university students. Sport Tk-Revista Euroamericana De Ciencias Del Deporte, 2017;6(2):39-47.

4. Kozlov SS, Sizova NV, Vasilets VV, Vrublevskiy EP. Individually-differentiated organization of training stimulation at step aerobics classes with middle aged women. Teoriya $i$ praktika fizicheskoy kultury, 2015;8:50-54. (in Russian)

5. Skidan AA, Vrublevskiy EP. Methods differentiate employment by improving shaping women of mature age. Izvestiia TulGU. Fizicheskaia kul tura. Sport, 2014;3:37-43. (in Russian)

6. Kohl HW, Murray TD. Foundations of Physical Activity and Public Health. Champaing: Human Kinetics; 2012.

7. Lisickaia TS. Fitness against aging. Moscow; 2016. (in Russian)

8. Vengerova NN. Pedagogical technologies of the fitness industry for maintaining health of women of mature age. 
Sankt Petersburg; 2011. (in Russian)

9. Bennett EV, Clarke LH, Kowalski KC, Crocker PRE. From pleasure and pride to the fear of decline: Exploring the emotions in older women's physical activity narratives. Psychology of Sport and Exercise. 2017;33:113- 22. https://doi.org/10.1016/j.psychsport.2017.08.012

10.Li Ynok. Complex physical rehabilitation of women of the second period of mature age with a metabolic syndrome. Cand. Diss. Moscow;; 2015. (in Russian)

11. Tret'iakova NV, Andriukhina TV, Ketrish EV. Theory and technique of improving physical culture. Moscow: Sports; 2016. (in Russian)

12.Sokolova IV. Modern improving technologies. Sankt Petersburg; 2014. (in Russian)

13. Seluianov VN. Technology of improving physical culture. Moscow: TVT Division; 2009. (in Russian)

14.Skidan A, Vrublevskiy E. Physical conditions monitoring system for mature women in the process of health-improving shaping activities. Sportivnij visnik Pridniprov'ia, 2017; 3: 177-183.

15.Batishcheva LD. Prevention of presenilation of women of mature age on the basis of a complex of means of improving physical culture. Cand. Diss. Maikop; 2007. (in Russian)

16.Stewart A, Sutton L. Body composition in sport, exercise and health. L.: Routledge; 2012. https://doi.org/10.4324/9780203133040

17.Skidan A, Vrublevskiy E. Somatometrical pecularities and motivation preferences of middle-aged women engaged in shaping. Sportivnij visnik Pridniprov'ia, 2016; 3: 207-211. (in Ukrainian)

18. Orlan AS. Creation of occupations improving physical culture of female teachers of 45-55 years on the basis of block and modular submission of the contents. Cand. Diss. Volgograd; 2017. (in Russian)

19.Aftimichuk OE. Theory and technique of fitness. Kishinev: Valinex; 2009. (in Russian)

20.Los' EE. Shaping: organization of independent occupations. Minsk; 2013. (in Russian)

21.Doherty J, Giles M, Gallagher AM, Simpson EEA. Understanding pre-, peri- and post-menopausal women's intentions to perform muscle-strengthening activities using the Theory of Planned Behaviour. Maturitas. 2018;109:89-96. https://doi.org/10.1016/j.maturitas.2017.12.014

22.Landa BKh. Technique of complex assessment of physical development and physical fitness. Moscow: Soviet sport; 2008. (in Russian)

23. Chernikova LP. Hormonal cycles of the woman. Rostov n D: Phoenix; 2003. (in Russian)

24. Sologubova SV. Combination of different types of fitness in sports and improving occupations with women of the first mature age. Cand. Diss. Dnipropetrovsk; 2012. (in Ukrainian)

25.Ivanova ZhA. Sports and improving occupations with women of mature age taking into account three phases OMTs. Cand. Diss. Sankt Petersburg; 2008. (in Russian)

26. Shakhlina LIa-G. Medicobiological bases of a sports training of women. Kiev: Scientific Thought; 2001. (in Russian)

\section{Information about the authors:}

Kostyuchenko V.F.; http://orcid.org/0000-0002-6242-5683; vf-kost@mail.ru; Faculty of Summer Olympic Sports, National State University of Physical Culture, Sports and Health named after P.F. Lesgafta; st. Decembrists, 35, St. Petersburg, 190121, Russia.

Skidan A.A. http://orcid.org/0000-0002-7270-888X; lady.skidan@mail.ru; Faculty of Physical Education, Gomel State University named after Fransysk Skarina; st. Soviet, 104, Gomel, 246019, Belarus.

Vrublevskiy E.P.; (Corresponding author); http://orcid.org/0000-0001-5053-7090; vru-evg@yandex.ru; Faculty of Physical Education, Gomel State University named after Fransysk Skarina; st. Soviet, 104, Gomel, 246019, Belarus.; Faculty of Medicine and Health Sciences, University of Zielona Góra; ul. Licealna 9, 65-417 Zielona Góra, Poland.

Cite this article as: Kostyuchenko VF, Skidan AA, Vrublevskiy EP. The individual differentiated training design of healthpromoting shaping with mature age women. Pedagogics, psychology, medical-biological problems of physical training and sports, 2018;22(6):295-300. https://doi.org/10.15561/18189172.2018.0603

The electronic version of this article is the complete one and can be found online at: http://www.sportpedagogy.org.ua/index.php/PPS/issue/archive

This is an Open Access article distributed under the terms of the Creative Commons Attribution License, which permits unrestricted use, distribution, and reproduction in any medium, provided the original work is properly cited (http://creativecommons.org/licenses/by/4.0/deed.en).

Received: 11.09 .2018

Accepted: 12.10.2018; Published: 22.12.2018 